Article

\title{
A Model of Solid Oxide Fuel Cell Degradation on a Microstructural Level
}

\author{
Marko Nerat \\ Jožef Stefan Institute, Jamova 39, SI-1000 Ljubljana, Slovenia; marko.nerat@ijs.si; Tel.: +386-147-737-14
}

Received: 19 February 2020; Accepted: 8 March 2020; Published: 11 March 2020

\begin{abstract}
The growth of nickel (Ni) particles in the porous anode is one of the most critical issues in solid oxide fuel cells (SOFC). It reduces the density of triple-phase boundaries (TPBs) over time and increases the polarization resistance of SOFC. Most of the three-dimensional models that are used to simulate this phenomenon in detail are numerically exhausting and as such intractable for on-line applications. This work presents a two-dimensional, microstructural model of reduced complexity as a trade-off between the numerical load and the level of detail. The model of Ni agglomeration is based on the power-law coarsening theory. The resulting model was validated by comparing the relative density of TPBs and the cell voltage to the experimentally measured values. It was shown that the calculated values closely fit the measured data. The advantage of the proposed model is that it takes lower computational load during the simulation compared to the complex phase field models and is suitable for estimation of SOFC electric performance over time.
\end{abstract}

Keywords: SOFC modeling; anode degradation; Ni agglomeration; TPB density reduction; conversion efficiency; electric energy yield estimation

\section{Introduction}

Solid oxide fuel cell (SOFC) systems are a promising technology for stationary applications since they convert hydrogen $\left(\mathrm{H}_{2}\right)$ directly into electricity at high conversion efficiency $(\eta)$ [1]. The $\eta$ of chemical to electrical energy is usually higher compared to the gas turbines or engines with internal combustion, which are limited by the Carnot cycle [2]. SOFCs can be fueled with some other hydrocarbon gases (e.g., methane) that need to be reformed externally in a reformer [3] or internally within the cell $[3,4]$. When the cell is fueled with hydrocarbon gas, the exhaust gas also contains carbon dioxide $\left(\mathrm{CO}_{2}\right)$. The major drawbacks of using SOFC systems are relatively high manufacturing costs and a fast degradation rate. The overall degradation of SOFC is commonly a combination of electrochemical degradation, structural degradation, and mechanical failure [5]. One of the most critical issues is structural degradation of the porous anode due to nickel (Ni) agglomeration. Ni agglomeration increases the polarization resistance of SOFC since it decreases the density of electrochemical reaction sites within the anode active layer.

Numerous experimental and theoretical studies have been conducted to elucidate the degradation processes. Electric performance losses were studied when the SOFC was fed with fuel containing poisonous gas [6]. It was found that sulfur (S) adsorbs on the nickel (Ni) surface within the porous anode layer and inhibits the reaction sites at triple-phase boundaries (TPBs). Consequently, an obvious drop in SOFC output voltage was observed in the initial few hours of the test. The degradation mechanisms occurring within a planar, nickel-yttria-stabilized zirconia (Ni-YSZ), anode-supported, SOFC with direct internal reforming of dry $\mathrm{CH}_{4}-\mathrm{CO}_{2}$ mixtures were investigated during the ageing tests [7]. One of the tests was conducted for about $300 \mathrm{~h}$ at the temperature of $770{ }^{\circ} \mathrm{C}$, current of $15 \mathrm{~A}$ (current density of $0.3 \mathrm{~A} \mathrm{~cm}^{-2}$ ), and the fuel utilization of $60 \%$. The $\mathrm{CH}_{4}$ and $\mathrm{CO}_{2}$ flow rates were both $43 \mathrm{~cm}^{3} \mathrm{~min}^{-1}$, whereas the airflow rate was $750 \mathrm{~cm}^{3} \mathrm{~min}^{-1}$. The SOFC output voltage decreased 
by about $20 \%$ in less than $300 \mathrm{~h}$ due to the deactivation of Ni particles as a consequence of carbon formation and deposition [7].

Industrial size $(10 \mathrm{~cm} \times 10 \mathrm{~cm})$, planar $\mathrm{SOFCs}$ were tested under various polarization conditions to show their degradation rate [8]. Post-mortem analysis of the microstructure revealed that the average size of Ni particles increased within the anode. Small Ni agglomeration occurred in the cell that operated under activation polarization (low current density), whereas large Ni agglomeration was observed in the cell operated under concentration polarization (high current density) [8]. This implies that the agglomeration of Ni particles has detrimental effects on electro-catalytic performance. The degradation reflects an increased polarization resistance of the anode that is attributed to the reduced density of TPBs within the anode due to the Ni grain coarsening [9].

Another paper [10] aims to predict the degradation of SOFC due to the growth of Ni particles. A theoretical approach to assess the agglomeration of Ni particles was adopted. A simple power law was employed to model the growth of average particle diameter over time. An excellent agreement with experimentally observed changes of the microstructure during the initial $1000 \mathrm{~h}$ of the test was accomplished. The change of TPB density was accounted for accordingly.

An improved phase field model was proposed recently [11] to simulate the microstructure evolution of the SOFC electrode. Three different sets of parameters for the YSZ/Ni anode, YSZ/lanthanum strontium manganite (LSM) cathode, and reference electrode were used to tune the interfacial energies in the model. The model was validated by simulating the grain growth and particle coarsening. The exponential growth of grain diameter with time was in good agreement with the simulation results presented in other studies. However, the electrical performances of presented SOFC microstructures were not calculated.

Many other studies deal with electric performances of SOFC, but the degradation models presented therein [12] cannot address the microstructural peculiarities of the anode and cathode layers, such as the spatial distribution of reaction sites, since these models are basically zero- or one-dimensional (0-D or 1-D). There is a paper [13] that addresses degradation of the SOFC due to different mechanisms, but it relies on very complex relations between the model parameters, such as length of TPBs and diameter of Ni grains, and microstructural properties. However, these relations are hard to prove when a limited set of measured data is available.

The majority of the approaches that rely on detailed 3-D models are numerically exhausting. In this work a trade-off between the numerical load and the level of precision of the degradation model was sought. Therefore, a reduced-complexity, 2-D model of Ni agglomeration in the anode layer was derived. The goal of this work was to study how the SOFC electric performance evolves with time. A simplified grain growth model was fitted by the density of TPBs that follows the degradation of microstructure. It was shown that the model is capable of predicting SOFC performance over a long period of time. Thus, the main contribution of this paper is a novel, two-dimensional (2-D) model that enables description of porous electrode properties on a microstructural level, but keeps numerical load at a reasonable level.

\section{Methods and Modeling}

The model takes into account species, mass, and charge conservation laws. The model is governed by partial differential equations that are described in Sections 2.1-2.3. Since the analytic solution of the system of equations could not be found, the equations were discretized with the finite difference method (FDM), adjusted according to the boundary conditions, as presented in Section 2.4, and solved numerically. A grey-scale image was used as the input of the model to define the cross-section profile of the SOFC, different phases (i.e., solid, electrolyte, and gas), and TPBs, as described in Sections 2.5 and 2.6. The degradation model is presented in Section 2.7, whereas the input parameters are listed in Section 2.8. The nomenclature used throughout the paper can be found in Abbreviation and Appendix A. 


\subsection{Conservation of Species}

Reduction Equation (1) and oxidation Equation (2) describe chemical reactions that occur at the TPBs within the porous cathode and anode:

$$
\begin{gathered}
\frac{1}{2} \mathrm{O}_{2}+2 \mathrm{e}^{-}=\mathrm{O}^{2-} \\
\mathrm{H}_{2}+\mathrm{O}^{2-}=\mathrm{H}_{2} \mathrm{O}+2 \mathrm{e}^{-}
\end{gathered}
$$

Since oxygen $\left(\mathrm{O}_{2}\right)$ in air and hydrogen $\left(\mathrm{H}_{2}\right)$ in fuel are consumed when SOFC operates as the electric source, their mass fractions $\left(y_{i}\right)$ within the pores are different from the mass fractions in the gas channels, so the conservation equation of gas species is written in the following form:

$$
\frac{\partial\left(\rho y_{\mathrm{i}}\right)}{\partial t}+\vec{\nabla} \cdot\left(\rho y_{\mathrm{i}} \vec{v}\right)+\vec{\nabla} \cdot \overrightarrow{j_{\mathrm{i}}}=S_{\mathrm{i}}
$$

Gas density is denoted with $\rho, y_{\mathrm{i}}$ is mass fraction of the $i$-th gas species (index $i$ or $j$ denotes $\mathrm{H}_{2}$, $\mathrm{H}_{2} \mathrm{O}, \mathrm{O}_{2}$ or $\mathrm{N}_{2}$ ), $v$ is the average velocity of mass flux, $j_{\mathrm{i}}$ is the $i$-th component of the diffusive mass flux, $S_{\mathrm{i}}$ is source or sink of the $i$-th gas species. Diffusion of gas species is modeled by considering

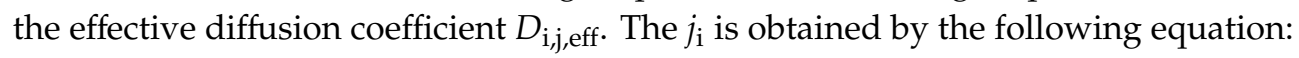

$$
\overrightarrow{j_{i}}=-\sum_{j=1}^{\mathrm{N}-1} \rho \cdot D_{\mathrm{i}, \mathrm{j}, \mathrm{eff}} \cdot \vec{\nabla} y_{\mathrm{j}}=-\sum_{\mathrm{j}=1}^{\mathrm{N}-1} \rho \cdot \mu^{\frac{3}{2}} \cdot D_{\mathrm{i}, \mathrm{j}} \cdot \vec{\nabla} y_{\mathrm{j}}
$$

$N$ denotes the number of gas species in gas mixture ( $N=2$ since only two gas species are present). The diffusion coefficient $D_{\mathrm{i}, \mathrm{j}}$ of a binary mixture of gas species $i$ and $j$ can be estimated as follows [14]:

$$
\begin{gathered}
D_{\mathrm{i}, \mathrm{j}}=\frac{10^{-7} \cdot T^{\frac{7}{4}}}{p \cdot M_{\mathrm{i}, \mathrm{j}}^{\frac{1}{2}} \cdot\left(V_{\mathrm{i}}^{\frac{1}{3}}+V_{\mathrm{j}}^{\frac{1}{3}}\right)^{2}} \\
M_{\mathrm{i}, \mathrm{j}}=\left(\frac{1}{M_{\mathrm{i}}}+\frac{1}{M_{\mathrm{j}}}\right)^{-1}
\end{gathered}
$$

$T$ is the temperature in Kelvin $(\mathrm{K}), p$ is the pressure in bar $\left(1 \mathrm{bar}=10^{5} \mathrm{~Pa}\right), \mathrm{M}_{\mathrm{i} / \mathrm{j}}$ is the molar mass $\left(\mathrm{g} \mathrm{mol}^{-1}\right.$ ) of gas species in the binary mixture, and $V_{\mathrm{i} / \mathrm{j}}$ is the diffusion volume in $\mathrm{cm}^{3}$. Detailed values of $M_{\mathrm{i}}$ and $V_{\mathrm{i}}$ can be found in one of our previous papers [15]. The $S_{\mathrm{i}}$ is calculated at the TPBs, where all three phases (i.e., solid, electrolyte, and gas) meet, otherwise it is zero. The fuel $\left(\mathrm{H}_{2}\right)$ is consumed and water $\left(\mathrm{H}_{2} \mathrm{O}\right)$ is produced at the TPBs in the anode as the SOFC operates, so the sink/source term $\left(S_{\mathrm{H}_{2}} / S_{\mathrm{H}_{2} \mathrm{O}}\right)$ depends on anode current $\left(i_{\mathrm{a}}\right)$. Faraday constant is denoted with $F=96,485 \mathrm{As} \mathrm{mol}^{-1}$.

$$
\begin{aligned}
S_{\mathrm{H}_{2}} & =-\frac{M_{\mathrm{H}_{2}} \cdot i_{\mathrm{a}}}{2 \cdot F} \\
S_{\mathrm{H}_{2} \mathrm{O}} & =+\frac{M_{\mathrm{H}_{2} \mathrm{O}} \cdot i_{\mathrm{a}}}{2 \cdot F}
\end{aligned}
$$

The oxygen $\left(\mathrm{O}_{2}\right)$ is consumed at the TPBs in the cathode as the SOFC operates, so the sink term $\left(S_{\mathrm{O}_{2}}\right)$ depends on cathode current $\left(i_{\mathrm{c}}\right)$ :

$$
S_{\mathrm{O}_{2}}=-\frac{M_{\mathrm{O}_{2}} \cdot i_{\mathrm{c}}}{2 \cdot F}
$$

It should be noted that nitrogen $\left(\mathrm{N}_{2}\right)$ is neither consumed nor produced, but its mass fraction depends on the mass fraction of oxygen, which changes within the pores as the SOFC operates at 
different output current. The mass fraction of water $\left(y_{\mathrm{H}_{2} \mathrm{O}}\right)$ is calculated as $1-y_{\mathrm{H}_{2}}$, whereas the mass fraction of nitrogen $\left(y_{\mathrm{N}_{2}}\right)$ is calculated as $1-y_{\mathrm{O}_{2}}$.

\subsection{Conservation of Mass}

The mass conservation equation is written in the following form:

$$
\frac{\partial \rho}{\partial t}+\vec{\nabla} \cdot(\rho \vec{v})=\sum_{\mathrm{i}=1}^{\mathrm{N}} S_{\mathrm{i}}
$$

The density of a gas is denoted with $\rho, v$ is the average velocity of mass flux, $S_{\mathrm{i}}$ represents sink or source of gas species, $\mathrm{N}$ is the number of gas species in the air or fuel. Since an ideal gas is assumed, the density of air $\left(\rho_{\text {air }}\right)$ and fuel $\left(\rho_{\text {fuel }}\right)$ depends on temperature $(T)$, total pressure $(p)$, and mass fraction of gas species $\left(y_{\mathrm{i}}\right)$. Ideal gas constant is denoted with $R=8.314 \mathrm{~J} \mathrm{~mol}^{-1} \mathrm{~K}^{-1}$.

$$
\begin{gathered}
\rho_{\text {air }}=\frac{p \cdot M_{\mathrm{O}_{2}} \cdot M_{\mathrm{N}_{2}}}{R \cdot T \cdot\left(y_{\mathrm{O}_{2}} \cdot M_{\mathrm{N}_{2}}+\left(1-y_{\mathrm{O}_{2}}\right) \cdot M_{\mathrm{O}_{2}}\right)} \\
\rho_{\text {fuel }}=\frac{p \cdot M_{\mathrm{H}_{2}} \cdot M_{\mathrm{H}_{2} \mathrm{O}}}{R \cdot T \cdot\left(y_{\mathrm{H}_{2}} \cdot M_{\mathrm{H}_{2} \mathrm{O}}+\left(1-y_{\mathrm{H}_{2}}\right) \cdot M_{\mathrm{H}_{2}}\right)}
\end{gathered}
$$

It should be noted that discretization of the divergence terms in Equations (3) and (10) should be done carefully, since $\rho_{\text {air/fuel }}$ changes within pores, and thus across each discretization step. If the central differencing scheme is used, $\rho_{\text {air/fuel }}$ should be evaluated in the middle of the two adjacent discretization points. A good approximation is obtained if the average mass fraction is used in Equations (11) and (12). Figure 1 shows the aforementioned situation schematically.

The density of gas is evaluated with:

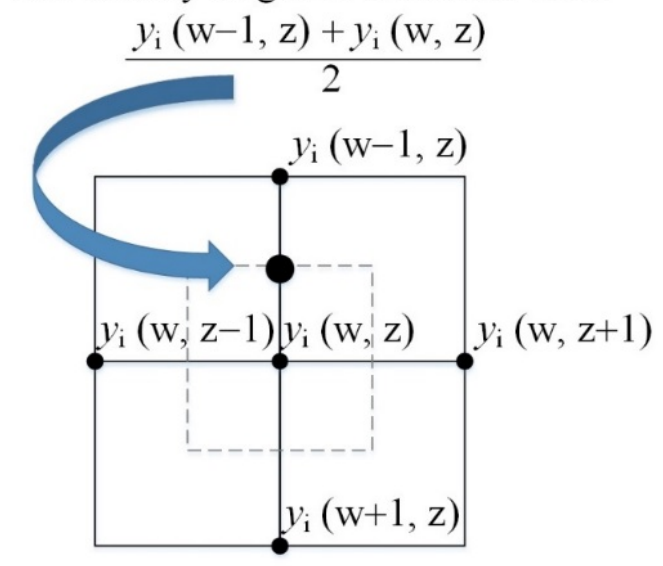

Figure 1. Illustration of the discretization mesh of species/mass conservation equation.

\subsection{Conservation of Charge}

The charge transfer through the modeled SOFC is described by different charge exchange mechanisms that are modeled in the following subsections. A schematic diagram is shown in Figure 2 to illustrate these mechanisms. Each number (1-5) in Figure 2 depicts the mechanism that is described in the equally numbered subsection. 


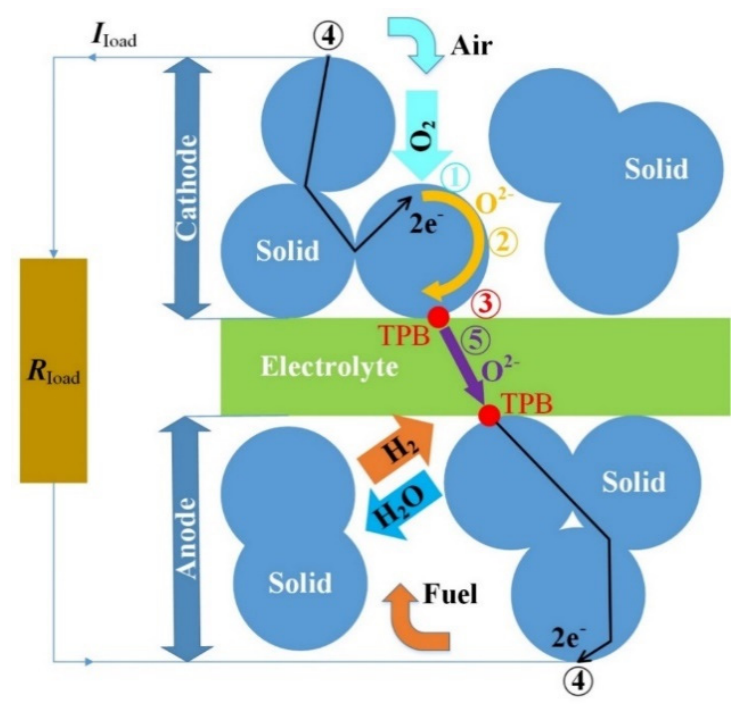

Figure 2. Illustrated charge transfer within the solid oxide fuel cell (SOFC).

\subsubsection{Surface Exchange}

It is assumed the oxygen $\left(\mathrm{O}_{2}\right)$ that fills the pores of solid (i.e., mixed ionic-electronic conductive-MIEC)) material is adsorbed into the cathode surface. Oxygen ions $\left(\mathrm{O}^{2-}\right)$ are formed with a double negative charge by accepting electrons $\left(\mathrm{e}^{-}\right)$from the cathode. The flow of $\mathrm{O}^{2-}\left(J_{\mathrm{O}^{2-}}\right)$ can be modeled as follows [16]:

$$
\vec{n} \cdot \vec{J}_{\mathrm{O}^{2-}}=-k_{\text {surf }} \cdot\left(C_{\mathrm{O}^{2-}, \text { eq }}-C_{\mathrm{O}^{2-}}\right)
$$

The surface exchange coefficient is denoted with $k_{\text {surf. }}$ It depends on the temperature and the partial pressure of $\mathrm{O}_{2}$. The equilibrium oxygen ion concentration is denoted with $C_{\mathrm{O}^{2-}}$, eq and depends on the partial pressure of $\mathrm{O}_{2}$ within pores. The concentration of oxygen ions $\left(\mathrm{C}_{\mathrm{O}^{2-}}\right)$ decreases during the increasing electric current load $\left(\mathrm{C}_{\mathrm{O}^{2-}}<\mathrm{C}_{\mathrm{O}^{2-}, \text { eq }}\right)$.

\subsubsection{Bulk Diffusion}

Since the electronic conductivity of the cathode MIEC material is high and should not limit the electric current, the diffusion of $\mathrm{O}^{2-}$ is assumed to limit the current. The diffusion of $\mathrm{O}^{2-}$ is modeled by using Fick's first law:

$$
\vec{J}_{\mathrm{O}^{2-}, \text { bulk }}=-D_{\text {chem }} \cdot \vec{\nabla} C_{\mathrm{O}^{2-}}
$$

$D_{\text {chem }}$ is chemical diffusion coefficient that depends on temperature and partial pressure of $\mathrm{O}_{2}$ [17].

\subsubsection{Charge Transfer}

At the interface between the solid MIEC and electrolyte material the $\mathrm{O}^{2-}$ are exchanged. The local charge transfer voltage (overpotential) is the driving force for this process [17]. The current density is modeled by the Butler-Volmer equation:

$$
i_{\mathrm{a} / \mathrm{c}}=\left\{\begin{array}{l}
i_{0, \mathrm{a}} \cdot\left[\exp \left(\frac{\alpha_{\mathrm{f}}^{\mathrm{a}} \cdot F \cdot\left(V_{\mathrm{s}}-V_{\mathrm{el}}-V_{0, \mathrm{a}}\right)}{R \cdot T}\right)-\exp \left(\frac{\alpha_{\mathrm{b}}^{\mathrm{a}} \cdot F \cdot\left(V_{\mathrm{s}}-V_{\mathrm{el}}-V_{0, \mathrm{a}}\right)}{R \cdot T}\right)\right] ; \text { at TPBs in the anode. } \\
i_{0, \mathrm{c}} \cdot\left[\exp \left(\frac{\alpha_{\mathrm{f}}^{\mathrm{c}} \cdot F \cdot\left(V_{\mathrm{s}}-V_{\mathrm{el}}-V_{0, \mathrm{c}}\right)}{R \cdot T}\right)-\exp \left(\frac{\alpha_{\mathrm{b}}^{\mathrm{c}} \cdot \mathrm{F} \cdot\left(V_{\mathrm{s}}-V_{\mathrm{el}}-V_{0, \mathrm{c}}\right)}{R \cdot T}\right)\right] ; \text { at TPBs in the cathode. }
\end{array}\right.
$$

The anode/cathode exchange current density is denoted with $\mathrm{i}_{0, \mathrm{a} / \mathrm{c}}$, forward/backward exponential coefficient of anode/cathode with $\alpha_{\mathrm{f} / \mathrm{b}}^{\mathrm{a} / \mathrm{c}}$ (for simplicity, $\alpha_{\mathrm{f}}^{\mathrm{a}}=0.5, \alpha_{\mathrm{f}}^{\mathrm{c}}=0.5, \alpha_{\mathrm{b}}^{\mathrm{a}}=-0.5, \alpha_{\mathrm{b}}^{\mathrm{c}}=-0.5$ are 
used), $V_{\mathrm{s}}$ is solid potential, $V_{\mathrm{el}}$ is electrolyte potential, and $V_{0, \mathrm{a} / \mathrm{c}}$ is anode/cathode potential that can be obtained from Nernst equation, respectively.

$$
\begin{gathered}
V_{0, \mathrm{a}}=0 \\
V_{0, \mathrm{c}}=\frac{-\Delta G_{\mathrm{H}_{2}}-k_{\mathrm{th}} \cdot T-R \cdot T \cdot \ln \left(\frac{p_{\mathrm{H}_{2}} \cdot \sqrt{P_{\mathrm{O}_{2}}}}{p_{\mathrm{H}_{2} \mathrm{O}}}\right)}{2 \cdot F}= \\
=\frac{-\Delta G_{\mathrm{H}_{2}}-k_{\mathrm{th}} \cdot T-R \cdot T \cdot \ln \left(\frac{y_{\mathrm{H}_{2}} \cdot M_{\mathrm{H}_{2} \mathrm{O}}}{\left(1-y_{\mathrm{H}_{2}}\right) \cdot M_{\mathrm{H}_{2}}} \cdot \sqrt{\frac{y_{\mathrm{O}_{2}} \cdot M_{\mathrm{N}_{2}}}{y_{\mathrm{O}_{2}} \cdot M_{\mathrm{N}_{2}}+\left(1-y_{\mathrm{O}_{2}}\right) \cdot \mathrm{M}_{\mathrm{O}_{2}}}}\right)}{2 \cdot F}
\end{gathered}
$$

Partial pressures of oxygen, hydrogen and water are denoted with $p_{\mathrm{O}_{2}}, p_{\mathrm{H}_{2}}$, and $p_{\mathrm{H}_{2} \mathrm{O}}$, respectively, and the $\Delta G_{\mathrm{H}_{2}}$ denotes Gibbs free energy for hydrogen. The temperature coefficient $k_{\text {th }}$ is calculated from Equation (17), considering open circuit voltage of measured SOFC (OCV $\left.=V_{0, \mathrm{c}}-V_{0, \mathrm{a}}\right)$, operating temperature, and partial pressures (or mass fractions) of gas species.

\subsubsection{Electronic Current}

Electronic current is modeled in solid MIEC material of the cathode by the continuity equation [17]:

$$
\vec{\nabla} \cdot\left(-\sigma_{\mathrm{s}, \mathrm{c}} \cdot \vec{\nabla} V_{\mathrm{s}}\right)+2 \cdot F \cdot \delta_{\mathrm{ads}}(\vec{r}) \cdot k_{\mathrm{surf}} \cdot\left(C_{\mathrm{O}^{2-}, \mathrm{eq}}-C_{\mathrm{O}^{2-}}\right)=0
$$
function:

The electronic conductivity of cathode MIEC material is denoted with $\sigma_{\mathrm{s}, \mathrm{c}}, \delta_{\mathrm{ads}}$ denotes delta

$$
\delta_{\text {ads }}(\vec{r})=\left\{\begin{array}{c}
1 ; \text { at MIEC } / \text { gas interface in cathode } \\
0 ; \text { elsewhere }
\end{array}\right.
$$

Similarly, the electronic current is modeled in solid MIEC material of anode:

$$
\vec{\nabla} \cdot\left(-\sigma_{\mathrm{s}, \mathrm{a}} \cdot \vec{\nabla} V_{\mathrm{s}}\right)+\delta_{\mathrm{a}}(\vec{r}) \cdot i_{\mathrm{a}}=0, \delta_{\mathrm{a}}(\vec{r})=\left\{\begin{array}{c}
1 ; \text { at TPB in anode } \\
0 ; \text { elsewhere }
\end{array}\right.
$$

The electronic conductivity of anode MIEC material is denoted with $\sigma_{\mathrm{s}, \mathrm{a}}, \delta_{\mathrm{a}}$ denotes delta function.

\subsubsection{Ionic Current}

The ionic current in anode/cathode/electrolyte is modeled with the continuity equation [17]:

$$
\vec{\nabla} \cdot\left(-\sigma_{\text {ion }, \mathrm{a} / \mathrm{c} / \mathrm{el}} \cdot \vec{\nabla} V_{\mathrm{el}}\right)-\delta_{\mathrm{a} / \mathrm{c}}(\vec{r}) \cdot i_{\mathrm{a} / \mathrm{c}}=0, \delta_{\mathrm{a} / \mathrm{c}}(\vec{r})=\left\{\begin{array}{c}
1 ; \text { at TPB in anode/cathode } \\
0 ; \text { elsewhere }
\end{array}\right.
$$

The ionic conductivity of anode/cathode/electrolyte is denoted with $\sigma_{\mathrm{ion}, \mathrm{a} / \mathrm{c} / \mathrm{el}}, \delta_{\mathrm{a} / \mathrm{c}}$ denotes delta function.

\subsection{Boundary Conditions}

Boundary conditions (BCs) have to be specified at different interfaces of the modeled SOFC structure in order to obtain a closed solution of the system of coupled partial differential equations. Figure 3 shows the interfaces A-K within the modeled domain, whereas a description of BCs at these interfaces is given in Table 1. 


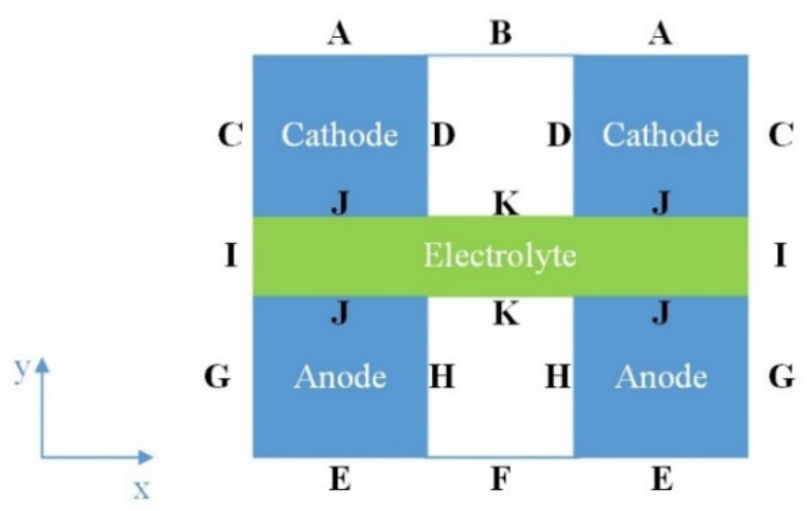

Figure 3. Schematic of interfaces in the modeled domain.

Table 1 . The boundary conditions.

\begin{tabular}{cccccc}
\hline Interfaces/Variables & $V_{\mathbf{s}}(\mathrm{V})$ & $V_{\mathrm{el}}(\mathrm{V})$ & $y_{\mathrm{i}}(/)$ & $v\left(\mathbf{m ~ s}^{-1}\right)$ & $\boldsymbol{C}\left(\mathbf{m o l ~ m}^{-3}\right)$ \\
\hline $\mathrm{A}$ & $V_{\mathrm{s}}=V_{0, \mathrm{c}}-V_{\mathrm{b}}$ & $\vec{n} \cdot \vec{J}_{\mathrm{el}}=0$ & $/$ & $/$ & $\vec{n} \cdot \vec{J}_{\mathrm{O}^{2-}}=0$ \\
\hline $\mathrm{B}$ & $/$ & $/$ & $y_{\mathrm{i}}=y_{0, \mathrm{O}_{2}}$ & $\partial v_{y} / \partial y=0$ & $/$ \\
\hline $\mathrm{C}$ & $\vec{n} \cdot \vec{J}_{\mathrm{s}}=0$ & $\vec{n} \cdot \vec{J}_{\mathrm{el}}=0$ & $/$ & $/$ & $\vec{n} \cdot \vec{J}_{\mathrm{O}^{2-}}=0$ \\
\hline $\mathrm{D}$ & $\vec{n} \cdot \vec{J}_{\mathrm{s}}=0$ & $\vec{n} \cdot \vec{J}_{\mathrm{el}}=0$ & $\vec{n} \cdot \vec{j}_{\mathrm{i}}=0$ & $v_{x}=0$ & $\vec{n} \cdot \vec{J}_{\mathrm{O}^{2-}}=0$ \\
\hline $\mathrm{E}$ & $V_{\mathrm{s}}=V_{0, \mathrm{a}}$ & $\vec{n} \cdot \vec{J}_{\mathrm{el}}=0$ & $/$ & $/$ & $/$ \\
\hline $\mathrm{F}$ & $/$ & $/$ & $y_{\mathrm{i}}=y_{0, \mathrm{H}_{2}}$ & $\partial v_{y} / \partial y=0$ & $/$ \\
\hline $\mathrm{G}$ & $\vec{n} \cdot \vec{J}_{\mathrm{s}}=0$ & $\vec{n} \cdot \vec{J}_{\mathrm{el}}=0$ & $/$ & $/$ & $/$ \\
\hline $\mathrm{H}$ & $\vec{n} \cdot \vec{J}_{\mathrm{s}}=0$ & $\vec{n} \cdot \vec{J}_{\mathrm{el}}=0$ & $\vec{n} \cdot \vec{j}_{\mathrm{i}}=0$ & $v_{x}=0$ & $/$ \\
\hline $\mathrm{I}$ & $/$ & $\vec{n} \cdot \vec{J}_{\mathrm{el}}=0$ & $/$ & $/$ & $/$ \\
\hline $\mathrm{J}$ & $\vec{n} \cdot \vec{J}_{\mathrm{s}}=0$ & $\vec{n} \cdot \vec{J}_{\mathrm{el}}=i_{\mathrm{a} / \mathrm{c}}$ & $/$ & $/$ & $\vec{n} \cdot \vec{J}_{\mathrm{O}^{2-}}=0$ \\
\hline $\mathrm{K}$ & $/$ & $\vec{n} \cdot \vec{J}_{\mathrm{el}}=0$ & $\vec{n} \cdot \vec{j}_{\mathrm{i}}=0$ & $v_{y}=0$ & $/$ \\
\hline
\end{tabular}

\subsection{Modeled Structure}

An image of a SOFC cross-section profile was used to define the geometry of modeled domains (cathode, electrolyte, and anode) within the SOFC. The image had to be processed properly to detect the three different phases (solid, electrolyte, and gas) present within the real SOFC. Different image processing algorithms can be found in the literature [18-20]. Many ideas of how to choose a global threshold have been already presented [19]. Most of these methods derive the threshold value using the properties of an image histogram. A similar problem of how to detect different phases from threshold values has been already addressed in Ref. [20]. It is assumed that the grey values of the phases are normally distributed and sufficiently apart from each other. Hence their superposition results in a local minimum between the two phases when inspected in the pixel histogram [20].

A simple algorithm for detecting the three different phases was developed in our case. First, a vector with 256 locations was created. Second, the pixels in the image that have a certain grey scale value (GSV) were counted and the sum was stored at the GSV-th location in the vector. This procedure was repeated for each GSV $\in[0,1, \ldots, 255]$. Third, three local maximums of the vector were sought. Each GSV at which a local maximum was found corresponded to one of the three different phases, considering these phases had normal distribution of the pixel number with respect to this GSV. Fourth, two local minimums were sought by considering each one as located between two maximums. Fifth, two threshold values were obtained from indexes of the locations in the vector, at which two local 
minimums were found. An example of detection of two threshold values that differentiate the three different phases from the grey-scale image is shown in Figure 4.

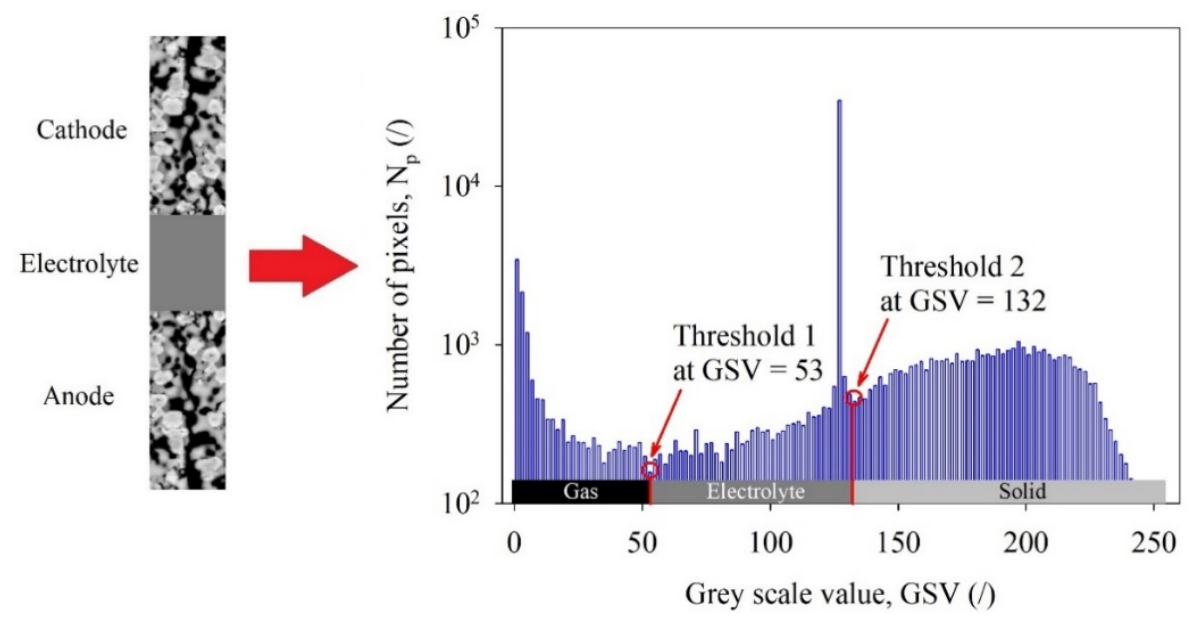

Figure 4. Detection of two threshold values to differentiate three phases from a grey-scale image [10].

\subsection{Solid-Electrolyte-Gas Interfaces}

Three different phases (solid, electrolyte, and gas phases) were initially set to zero values at each discretized location $(\mathrm{w}, \mathrm{z})$ of the modeled SOFC. These phases had to be unambiguously determined based on two threshold values, which were resolved as described in Section 2.5. The following criteria were considered:

- $\quad$ if $(\mathrm{GSV}<$ Threshold 1$)$ then Gas $(\mathrm{w}, \mathrm{z})=1$;

- $\quad$ else if $((G S V \geq$ Threshold 1$)$ and (GSV < Threshold 2)) then Electrolyte $(w, z)=1$;

- $\quad$ else Solid $(\mathrm{w}, \mathrm{z})=1$;

In the next step, only the connected (percolated) solid and electrolyte phases were determined in between the electric contacts, which were denoted as interfaces A and E in Figure 3. The connected gas phases to interface $B$ and $F$ were determined. For example, delta function $\delta_{\mathrm{a} / \mathrm{c}}(\mathrm{w}, \mathrm{z})=1$ since TPB was active within the porous anode or cathode if all three phases ere percolated and met in a single point $(\mathrm{w}, \mathrm{z})$. Otherwise, $\delta_{\mathrm{a} / \mathrm{c}}(\mathrm{w}, \mathrm{z})=0$ since TPB was inactive. This situation is shown schematically in Figure 5a. The upper part of Figure $5 b$ shows active TPBs within the modeled SOFC. The lower part of Figure $5 b$ shows the actual 2-D profile of the mass fraction ( $Y$ ) of $\mathrm{O}_{2}$ and $\mathrm{H}_{2}$ that corresponds to the percolated gas phase within the porous cathode and anode, respectively, as seen in the upper part. Please note that TPB detection actually needs four neighboring pixels (i.e., a small image of $2 \times$ 2 pixels) that represent different phases. It is obvious that TPB detection strongly depends on both threshold levels. Consequently, there is some uncertainty in this kind of detection, as it is impossible to determine whether a TPB at the interface really exists or not. Moreover, the reconstruction of porous material in this paper was based on the 2-D grey-scale image, which may introduce additional uncertainty. Detailed analysis and detection of TPB would require three-dimensional (3-D) tomography techniques, e.g., focused ion beam-scanning electronic microscopy (FIB-SEM) [21] and X-ray computed tomography (CT) [22]. Those provide more accurate SOFC microstructure characterization. These cutting-edge 3-D characterization techniques are very expensive and time-consuming [23]. This is why the detection in our case was restricted to 2-D grey-scale images only. 


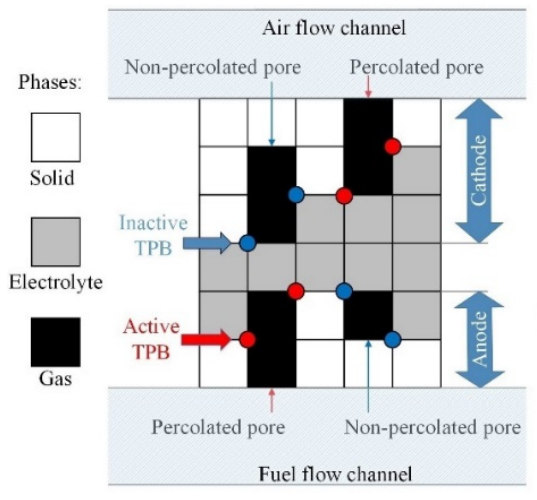

(a)

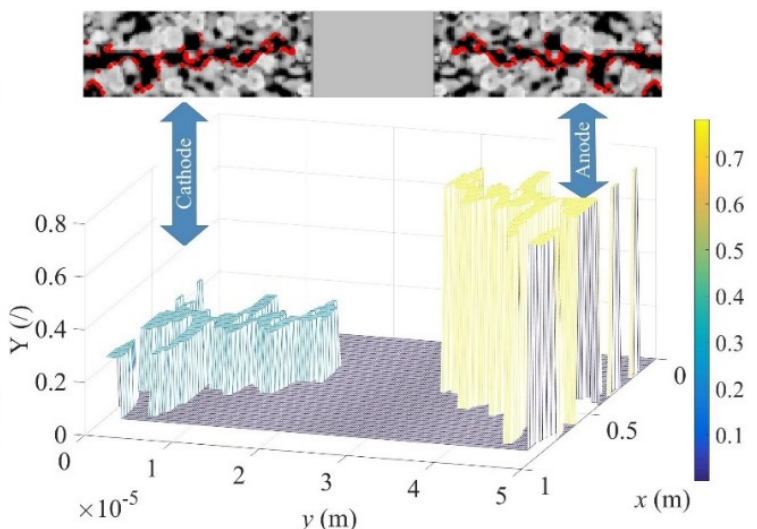

(b)

Figure 5. (a) Schematic explanation of the detection of active triple phase boundary (TPB) and (b) percolated gas phases.

\subsection{The Degradation Model}

Degradation mechanisms of SOFC have been studied experimentally [24,25] and theoretically [11] to investigate how the microstructure evolves over long-term operation under different conditions, such as temperature, current density [24,25], and initial composition of the porous anode, and the average size of Ni and YSZ grains within the microstructure [11].

Since a real SOFC operates at high temperatures (at $T=800-1000^{\circ} \mathrm{C}$ ), the microstructure evolution, such as grain growth or particle coarsening, is significant [11]. The microstructure becomes increasingly coarser and denser with increasing testing temperature, current density, and testing time [24]. At $750^{\circ} \mathrm{C}$ an increase in grain size occurs mainly in the bulk and interface compared with a non-degraded cell. At $850^{\circ} \mathrm{C}$ and above, the grain coarsening in the bulk becomes more pronounced than at $750{ }^{\circ} \mathrm{C}$. The coarsened interface region is about $1-2 \mu \mathrm{m}$ in width at $850^{\circ} \mathrm{C}$ and up to $5 \mu \mathrm{m}$ at $950{ }^{\circ} \mathrm{C}$. It was also seen that at $850^{\circ} \mathrm{C}$ the process of grain coarsening and interface densification continues with increasing testing time up to $17,500 \mathrm{~h}$ [24]. From these results one can note that microstructure evolution generally progresses with increasing temperature and testing time. Ostwald-ripening is an important mechanism of Ni coarsening in SOFC anode [26]. It occurs due to the transport of volatile Ni species via the gas phase and diffusion of vacancies, driven by different grain sizes.

Despite the detailed studies, only a few papers $[27,28]$ deal with the problem of how the microstructural degradation actually affects the electric performance of SOFC. In this paper the electric performance of a degraded SOFC was calculated by adjusting fewer parameters compared to the number of parameters that need to be set in the phase field model [11]. Moreover, the validation of such a model would require detailed analysis with three-dimensional (3-D) tomography techniques. These techniques have shown that the Ni (YSZ) grains grow exponentially with time [9]. Therefore, the degradation of SOFC due to grain growth was modeled by considering the power law [9]:

$$
d^{\kappa}=d_{0}{ }^{\kappa}+k \cdot t
$$

Time-dependent diameter of $\mathrm{Ni}$ grains is denoted with $d$, initial diameter with $d_{0}$, growth coefficient with $k$ and time with $t$. The exponential coefficient is denoted with $\mathrm{k}$. It equals 2 for grain growth and 3 for particle coarsening due to Ostwald-ripening [11].

However, Equation (22) has to be slightly adapted for numerical implementation. It is assumed that $d_{0}$ is determined by the minimum distance between the two adjacent points where active TPBs are located. This simplification is done due to problems with detecting grain boundaries of the $\mathrm{Ni}$ (YSZ) particles and their actual diameter by processing a grey-scale image. Moreover, reconstruction of the porous anode according to the phase field model would be necessary if actual grain growth was 
considered rigorously [11]. That is beyond the scope of the present paper, so the following algorithm was proposed.

First, the active TPBs are resolved as described in Section 2.6. Second, two vectors are defined for storing two distances $\left(d_{1, \min }, d_{2, \min }\right)$ from one to the closest two TPB points. Third, $d_{1, \min }$ and $d_{2, \min }$ are found. Fourth, the SOFC model is evaluated at each iteration (q) using a fixed time step $(\Delta t)$. Fifth, the following condition is checked at each iteration and at each active TPB point:

$$
\operatorname{if}\left(\left(d_{1, \min }(\mathrm{w}, \mathrm{z})[\mathrm{q}]+d_{2, \min }(\mathrm{w}, \mathrm{z})[\mathrm{q}]\right)^{\kappa}<\left(d_{1, \min }(\mathrm{w}, \mathrm{z})[\mathrm{q}]\right)^{\kappa}+\mathrm{q} \cdot k \cdot \Delta t\right) \text { then } \delta_{\mathrm{a}}(\mathrm{w}, \mathrm{z})=0
$$

This algorithm runs iteratively as long as it is defined by a maximum number of iterations q. It should be noted that after a certain number of iterations, the condition in Equation (23) is fulfilled at some active TPB point and this TPB is deactivated $\left(\delta_{\mathrm{a}}(\mathrm{w}, \mathrm{z})=0\right)$. In this way, the particle diameter is increased. It is important to note the number of active TPBs is decreased, so this model enables fitting the parameters $k$ and $n$ to achieve good approximation to results of measured or calculated relative TPB density from the literature $[10,11]$.

\subsection{Model Parameters}

Detailed descriptions of measured SOFC, including the lanthanum strontium cobalt ferrite (LSCF) cathode, Ni-scandia stabilized zirconia (Ni-SSZ) active (or support) anode layer, and electrolyte bilayer, can be found in Ref. [10]. The physical parameters are adopted from the literature, or fitted to match the desired characteristics of measured SOFC. Table 2 shows the list of input parameters.

Table 2. Input parameters of the SOFC model.

\begin{tabular}{|c|c|c|c|c|}
\hline Parameter & Symbol & Value & Unit & Reference \\
\hline Pressure & $p$ & 1.0 & bar & {$[10]$} \\
\hline Anode thickness & $d_{\mathrm{a}}$ & 20 & $\mu \mathrm{m}$ & [10] \\
\hline Cathode thickness & $d_{\mathrm{c}}$ & 20 & $\mu \mathrm{m}$ & [10] \\
\hline Electrolyte thickness & $d_{\mathrm{e}}$ & 10 & $\mu \mathrm{m}$ & [10] \\
\hline Anode electronic conductivity & $\sigma_{\mathrm{s}, \mathrm{a}}$ & 4800 & $\mathrm{~S} \mathrm{~m}^{-1}$ & {$[15]$} \\
\hline Cathode electronic conductivity & $\sigma_{\mathrm{s}, \mathrm{c}}$ & 1600 & $\mathrm{~S} \mathrm{~m}^{-1}$ & [15] \\
\hline Anode ionic conductivity & $\sigma_{\mathrm{el}, \mathrm{a}}$ & 2.0 & $\mathrm{~S} \mathrm{~m}^{-1}$ & [29] \\
\hline Cathode ionic conductivity & $\sigma_{\mathrm{el}, \mathrm{c}}$ & 2.0 & $\mathrm{~S} \mathrm{~m}^{-1}$ & [29] \\
\hline Electrolyte ionic conductivity & $\sigma_{\mathrm{el}, \mathrm{e}}$ & 2.0 & $\mathrm{~S} \mathrm{~m}^{-1}$ & [29] \\
\hline Anode exchange current density & $i_{0, \mathrm{a}}$ & 1200 & $\mathrm{~A} \mathrm{~m}^{-2}$ & {$[10]$} \\
\hline Cathode exchange current density & $i_{0, \mathrm{c}}$ & 2200 & $\mathrm{~A} \mathrm{~m}^{-2}$ & [10] \\
\hline Surface exchange coefficient & $k_{\text {surf }}$ & $2.0 \times 10^{-5}$ & $\mathrm{~m} \mathrm{~s}^{-1}$ & [17] \\
\hline Concentration of oxygen ions & $\mathrm{C}_{\mathrm{O}^{2-}}$ & $8.3 \times 10^{4}$ & $\mathrm{~mol} \mathrm{~m}^{-3}$ & [17] \\
\hline Chemical diffusion coefficient & $D_{\text {chem }}$ & $4.4 \times 10^{-10}$ & $\mathrm{~m}^{2} \mathrm{~s}^{-1}$ & [17] \\
\hline Series resistance of anode support layer & $R_{\mathrm{s}, \mathrm{a}}$ & 0.5 & $\Omega \mathrm{cm}^{2}$ & {$[10]$} \\
\hline Double layer capacitance of anode & $C_{\mathrm{dl}, \mathrm{a}}$ & 0.5 & $\mathrm{~F} \mathrm{~cm}^{-2}$ & {$[10]$} \\
\hline Molar fraction of hydrogen in fuel & $x_{0, \mathrm{H}_{2}}$ & 0.970 & I & {$[10]$} \\
\hline Molar fraction of water in fuel & $x_{0, \mathrm{H}_{2} \mathrm{O}}$ & 0.030 & I & [10] \\
\hline Molar fraction of oxygen in air & $x_{0, \mathrm{O}_{2}}$ & 0.207 & l & {$[10]$} \\
\hline Molar fraction of nitrogen in air & $x_{0, \mathrm{~N}_{2}}$ & 0.793 & l & [10] \\
\hline
\end{tabular}




\section{Results and Discussion}

The SOFC electric performance is simulated by using the model according the parameters in Table 2. We start with AC analysis because it is intended to adjust the anode/cathode exchange current density $\left(i_{0, a / c}\right)$ and qualitatively validate the simulation results with measured electro-impedance spectrum (EIS) in Ref. [10]. Note that the adjustment of $i_{0, \mathrm{a} / \mathrm{c}}$ should be done initially for online application of the model in practice, by fitting the calculated and measured EIS. Exact fitting of the EIS was not of the primary concern in this study case, but rather to achieve similar trends of simulated and measured EIS curves.

\subsection{AC Analysis}

The modeled cell was perturbed at OCV, according to the measurement results in Ref. [10], with sinusoidal voltage with the amplitude $14 \mathrm{mV}$. The frequency $(f)$ of voltage signal was set to each of 31 logarithmically equally spaced values of frequency from $0.1 \mathrm{~Hz}$ to $100 \mathrm{~Hz}$ to simulate the EIS. The temperature was set to $900{ }^{\circ} \mathrm{C}$. Other input parameters of the model can be found in Table 2. Figure 6 shows EIS of (a) non-degraded (i.e., at time $t=0 \mathrm{~h}$ ) and (b) degraded SOFC (i.e., at time $t=1000 \mathrm{~h}$ ). The low-range frequency arc was attributed to the anode charge transfer, whereas the mid-range frequency arc was correlated with charge transfer and surface exchange process in the cathode.

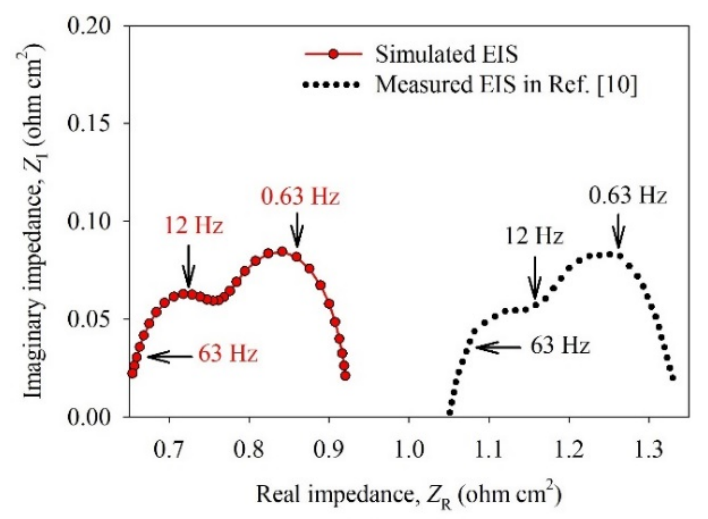

(a)

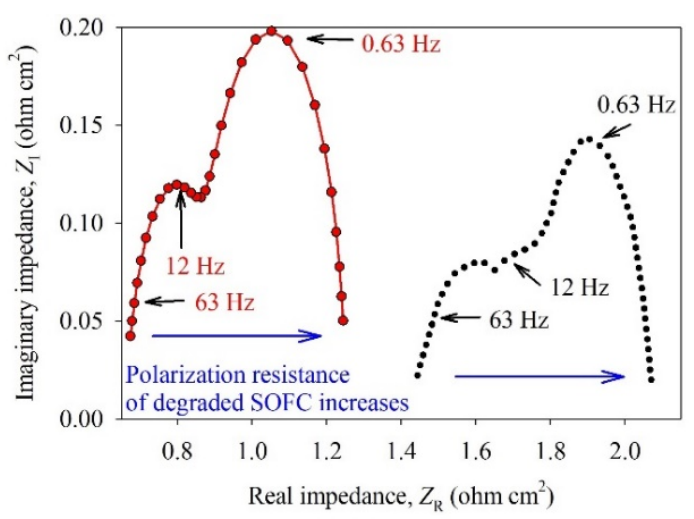

(b)

Figure 6. Electro-impedance spectrum (EIS) of (a) non-degraded SOFC (at time $t=0 \mathrm{~h}$ ) and (b) degraded SOFC (at time $t=1000 \mathrm{~h}$ ). Three different frequencies $(f=0.63,12$, and $63 \mathrm{~Hz})$ are labeled for guidance.

The anode and cathode polarization resistances increase over time (i.e., from 0 to $1000 \mathrm{~h}$ ) due to the reduced density of TPBs within the anode and cathode. The increased polarization resistance of the degraded SOFC indicated a correct trend regarding the time evolution of measured EIS, as can also be seen in Figure 8c in Ref. [10]. The measured series resistances were higher than in this case, which may be attributed to the wiring and contact resistances, which were not considered in the presented model. Moreover, if considering only the series resistances (about $1.05 \Omega \mathrm{cm}^{2}$ at non-degraded and $1.4 \Omega \mathrm{cm}^{2}$ at the degraded cell) that can be deduced from measured EIS, the voltage drop of SOFC would be about $0.47 \mathrm{~V}$ and $0.63 \mathrm{~V}$ at the current density $(J)$ of $0.45 \mathrm{~A} \mathrm{~cm}^{-2}$, so the direct current (DC) voltage of the SOFC ( $\left.V_{\text {cell }}\right)$ should be lower than shown in Figure 8a in Ref. [10]. The measured $V_{\text {cell }}$ of non-degraded SOFC was about $0.56 \mathrm{~V}$ (at time $t=0 \mathrm{~h}$ ), whereas $V_{\text {cell }}$ of degraded SOFC was about $0.42 \mathrm{~V}$ (at time $t=1000 \mathrm{~h}$ ).

Since the open circuit voltage (OCV) of SOFC is about $0.97 \mathrm{~V}$, the measured $V_{\text {cell }}$ should have been $0.50 \mathrm{~V}$ and $0.34 \mathrm{~V}$ when the aforementioned voltage drops were considered, respectively. Due to these discrepancies, the model was fitted only to reproduce the degradation of $V_{\text {cell }}$, as presented in Section 3.2, since we focus on calculating the electric performance of SOFC over time. However, a profound inspection of the measurement equipment and physical parameters of the real SOFC device 
would be necessary to obtain a better fitting of EIS, whereas a comparison of impedances could be done only if detailed measurement data were available in Ref. [10].

\subsection{Analysis}

In the second set of experiments, the DC analysis was performed. A comparison between calculated and measured electric performance of SOFC was done to address more realistic degradation due to the coarsening of Ni particles within the anode. A fraction of backscattered electron (BSE) microscope pictures were taken from Figure 3a in Ref. [10] to define an approximation to the real structure of porous anode. The experimental degradation test was performed for $1000 \mathrm{~h}$ at the temperature of $900{ }^{\circ} \mathrm{C}$ and at current density of $0.45 \mathrm{~A} \mathrm{~cm}^{-2}$, whereas $3 \mathrm{vol} \%$ humidified $\mathrm{H}_{2}$ was supplied to the anode and air was supplied on the cathode side. The flow rates of hydrogen and air were $350 \mathrm{~cm}^{3} \mathrm{~min}^{-1}$ and $1500 \mathrm{~cm}^{3} \mathrm{~min}^{-1}$, respectively [10]. Due to this, the temperature and current density of the modeled SOFC was set to $T_{\text {cell }}=900{ }^{\circ} \mathrm{C}$ and $J_{\text {cell }}=0.45 \mathrm{~A} \mathrm{~cm}^{-2}$, respectively, during the simulation from 0 to $1000 \mathrm{~h}$. Time increment $\Delta t=100 \mathrm{~h}$ was used since the experimental data was defined at $100 \mathrm{~h}$ intervals in Ref. [10]. The anode exponential coefficient $\left(\kappa_{a}=3\right)$ and the anode growth coefficient $\left(k_{\mathrm{a}}=2.1 \times 10^{-21} \mathrm{~m}^{3} \mathrm{~h}^{-1}\right)$ were manually fitted to match the relative TPB density of the measured SOFC in Ref. [10].

Figure 7a shows relative TPB density in the anode $\left(\mathrm{TPB}_{\mathrm{a}}\right)$ and in the cathode $\left(\mathrm{TPB}_{\mathrm{c}}\right)$ as a function of time. The calculated relative $\mathrm{TPB}_{\mathrm{a}}$ density had a similar profile as that in Figure 8d in Ref. [10]. The initial absolute value of $\mathrm{TPB}_{\mathrm{a}}(t=0 \mathrm{~h})$ was approximately four times lower $\left(0.7 \mu \mathrm{m}^{-2} \mathrm{vs} .2 .9 \mu \mathrm{m}^{-2}\right)$, but another study revealed [30] that the density of active TPBs may be lower $\left(0.74 \mu^{-2}\right)$. Since the TPBs that lie in the third dimension (i.e., in the plane of 2-D grey-scale image) cannot be resolved with our algorithm, it was obvious why the obtained density of TPBs from 2-D grey-scale image was lower. Although the TPB density was lower in our case than it should have been (or than it was in the real SOFC), it could be compensated for with higher activity of TPBs (i.e., higher exchange current density, $\left.i_{0, \mathrm{a} / \mathrm{c}}\right)$ to achieve a similar electric performance of modeled SOFC. It is important to note the presented model approximated the spatial distribution of TPBs in real SOFC. Due to this, it could be expected that the simulation results may be more reliable compared to those obtained with 0 -D or 1-D models.

Figure $7 \mathrm{~b}$ shows the calculated voltage $\left(V_{\mathrm{da}}\right)$ of SOFC, with degraded anode, which is almost the same as the reference voltage ( $V_{\text {Ref. [10] }}$ in Figure 8a in Ref. [10]) from 0 to $100 \mathrm{~h}$, whereas a higher voltage difference $(0.03-0.06 \mathrm{~V})$ were noticed from $200 \mathrm{~h}$ to $1000 \mathrm{~h}$. This difference may be partly attributed to a noticeable drop of open circuit voltage $(\triangle \mathrm{OCV}=0.02 \mathrm{~V})$ that occurs in real SOFC at $t=200 \mathrm{~h}$, as seen in Figure 8a in Ref. [10], and partly to some other degradation processes that possibly were going on concurrently. The $\triangle \mathrm{OCV}$ was attributed to different agents. Since $\mathrm{OCV}=V_{0, \mathrm{c}}-V_{0, \mathrm{a}}$ depends on mass fraction of hydrogen $\left(y_{0}, \mathrm{H}_{2}\right)$, referring to Equation (17), it can be speculated that $y_{0, \mathrm{H}_{2}}$ was slightly decreased due to increased humidity in the fuel or hydrogen gas leak. To achieve this, the input molar fraction of hydrogen $\left(x_{0, \mathrm{H}_{2}}\right)$ was adjusted to 0.955 in order to simulate $\triangle \mathrm{OCV}$ at $t=200 \mathrm{~h}$. 


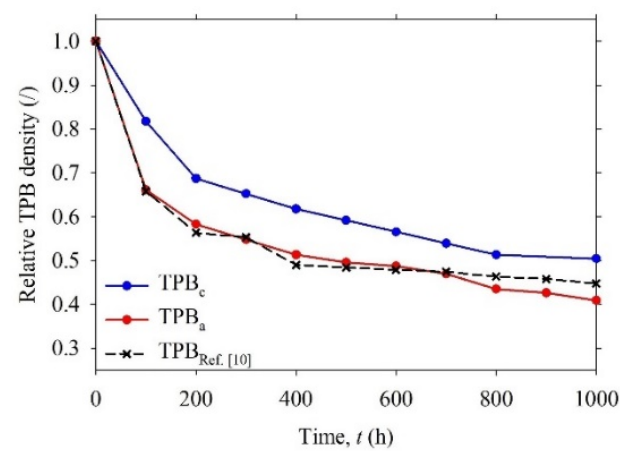

(a)

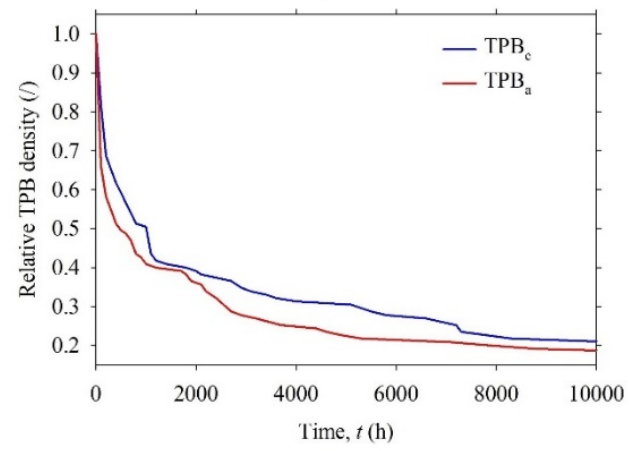

(c)

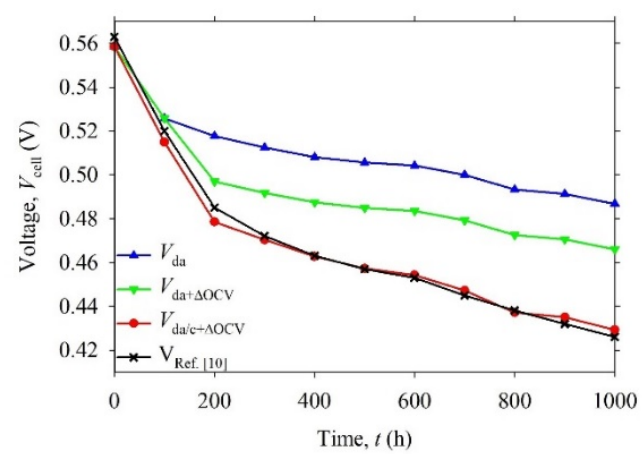

(b)

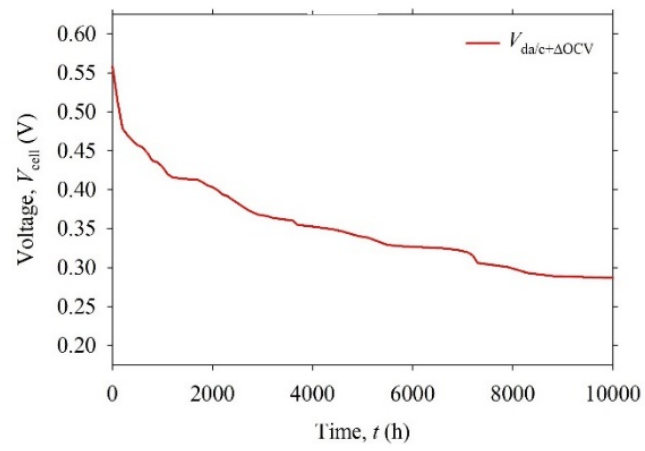

(d)

Figure 7. (a) Relative TPB density and (b) output voltage $\left(V_{\text {cell }}\right)$ of the SOFC as a function of time from 0 to $1000 \mathrm{~h}$. (c) Relative TPB density and (d) output voltage $\left(V_{\text {cell }}\right)$ of the SOFC as a function of time from 0 to $10,000 \mathrm{~h}$. The anode and cathode exponential coefficients, $\kappa_{\mathrm{a}}=3$ and $\mathrm{k}_{\mathrm{c}}=3$, and the anode and cathode growth coefficients, $k_{\mathrm{a}}=2.1 \times 10^{-21} \mathrm{~m}^{3} \mathrm{~h}^{-1}$ and $k_{\mathrm{c}}=1.4 \times 10^{-21} \mathrm{~m}^{3} \mathrm{~h}^{-1}$, are considered.

The voltage $\left(V_{\mathrm{da}+\Delta \mathrm{OCV}}\right)$ of $\mathrm{SOFC}$, with degraded anode and $\triangle \mathrm{OCV}$, followed the reference voltage ( $\left.V_{\text {Ref. [10] }}\right)$ from 0 to $200 \mathrm{~h}$, but the difference between $V_{\text {da }+\Delta \mathrm{OCV}}$ and $V_{\text {Ref. [10] }}$ that remained was probably attributed to some other degradation processes. The grain coarsening possibly occurred in the SOFC cathode due to high temperature $\left(900^{\circ} \mathrm{C}\right)$ [24], although there was no data about it in Ref. [10]. In order to reproduce the higher degradation rate of $V_{\text {Ref. [10] }}$ the grain coarsening was also modeled in the SOFC cathode (growth coefficient $k_{\mathrm{c}}=1.4 \times 10^{-21} \mathrm{~m}^{3} \mathrm{~h}^{-1}$ and cathode exponential coefficient $k_{c}=3$ ) The values were manually fitted to achieve a minimum standard deviation between the voltage $\left(V_{\mathrm{da} / \mathrm{c}+\Delta \mathrm{OCV}}\right)$ of $\mathrm{SOFC}$, with degraded anode/cathode and $\triangle \mathrm{OCV}$, and $V_{\text {Ref. [10] }}$. It should be noted that using the model for online estimation of SOFC degradation would require similar fitting procedure. The parameters $\mathrm{k}_{\mathrm{a} / \mathrm{c}}$ and $\mathrm{k}_{\mathrm{a} / \mathrm{c}}$ should be fitted automatically on the measured voltage profile within the first few $100 \mathrm{~h}$ intervals.

In Figure $7 \mathrm{~b}, V_{\mathrm{da} / \mathrm{c}+\Delta \mathrm{OCV}}$ closely followed $V_{\text {Ref. [10] }}$ if the degradation due to the grain coarsening was modeled in both electrodes. The maximum absolute difference between the $V_{\mathrm{da} / \mathrm{c}+\Delta \mathrm{OCV}}$ and $V_{\mathrm{Ref}}$. [10] was about $7 \mathrm{mV}$, whereas standard deviation was about $3 \mathrm{mV}$. Both values were negligibly small. The absolute degradation rate of $V_{\text {Ref. [10] }}$ from 0 to $1000 \mathrm{~h}$ was estimated to be $0.14 \mathrm{~V} \mathrm{kh}^{-1}$, whereas the relative degradation rate was about $25 \% \mathrm{kh}^{-1}$. The $V_{\mathrm{da} / \mathrm{c}+\Delta \mathrm{OCV}}$ had similar degradation rates. These rates were very high, most probably due to high operating temperature $900{ }^{\circ} \mathrm{C}$, which was close to the melting point of the materials, so the agglomeration of grains progressed very quickly, as already argued in Ref. [10].

After the fitting procedure, the model was used to calculate the degradation of SOFC electric performance in the range of 10,000 $\mathrm{h}$, which was a common operating period [24]. Two additional plots, as seen in Figure 7c,d, were added to show the calculated degradation of the modeled SOFC. It can be noticed that the relative TPB density of anode (cathode) dropped to about $0.18(0.21)$, whereas the $V_{\mathrm{da} / \mathrm{c}+\Delta \mathrm{OCV}}$ dropped to about $0.28 \mathrm{~V}$ at $10,000 \mathrm{~h}$. In other words, in this period of time, 


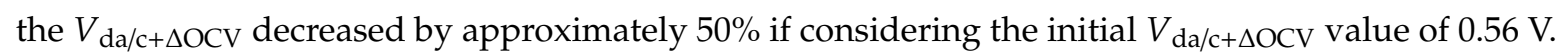
To show how the degradation affects the electric conversion efficiency $(\eta)$ of the SOFC, the $\eta$ was evaluated at every $\Delta t=100 \mathrm{~h}$ from 0 to $1000 \mathrm{~h}$, according to the following equation:

$$
\eta=\frac{P_{\mathrm{el}}}{P_{\mathrm{in}}}=\frac{P_{\mathrm{el}}}{\Phi_{\mathrm{in}, \mathrm{H}_{2}} \cdot \Delta H_{\mathrm{H}_{2}}}=\frac{2 \cdot F \cdot V_{\mathrm{cell}}}{\Delta H_{\mathrm{H}_{2}}}
$$

The $P_{\mathrm{el}}$ is electric power density, $P_{\mathrm{in}}$ is input power density, $\Phi_{\mathrm{in}, \mathrm{H}_{2}}$ is input molar flux of hydrogen. It can be noticed that $\eta$ depends on the output voltage of SOFC ( $\left.V_{\text {cell }}\right)$, Faraday constant $(F)$, and standard enthalpy of formation for hydrogen $\left(\Delta H_{\mathrm{H}_{2}}\right)$ only if it is assumed that each oxidized $\mathrm{H}_{2}$ contributes two electrons, Equation (2). Figure 8a shows the $\eta$ of the SOFC as a function of time. The reference conversion efficiency ( $\eta_{\text {Ref. [10] }}$ ) dropped rapidly from 0 to $200 \mathrm{~h}$ and moderately from $200 \mathrm{~h}$ to $1000 \mathrm{~h}$ (by approximately 0.07 and 0.04 , respectively). A similar trend of the conversion efficiency $\left(\eta_{\mathrm{da} / \mathrm{c}+\triangle \mathrm{OCV}}\right)$ of SOFC, with degraded anode/cathode and $\triangle \mathrm{OCV}$, was observed. The absolute degradation rate of $\eta_{\text {Ref. [10] }}$ from 0 to $1000 \mathrm{~h}$ was estimated to be $0.11 \mathrm{kh}^{-1}$, whereas the relative degradation rate was about $25 \% \mathrm{kh}^{-1}$. Similar degradation rates of $\eta_{\mathrm{da} / \mathrm{c}+\Delta \mathrm{OCV}}$ were noticed. These values were high, but it should be noted that the real SOFC degradation test was performed at high temperature $\left(900^{\circ} \mathrm{C}\right)$. The details about the experimental test can be found in Ref. [10].

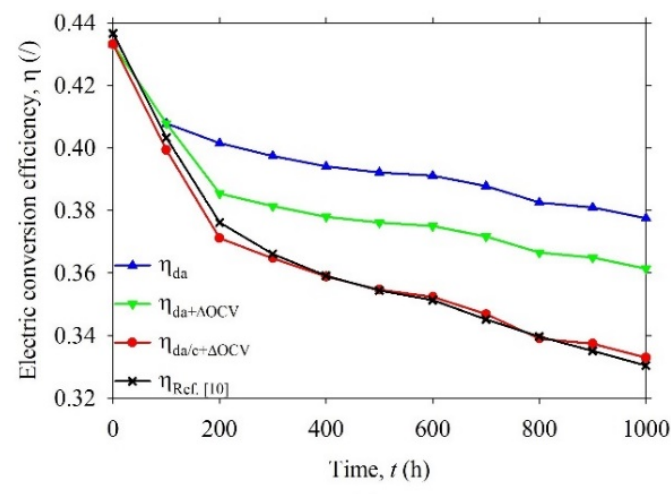

(a)

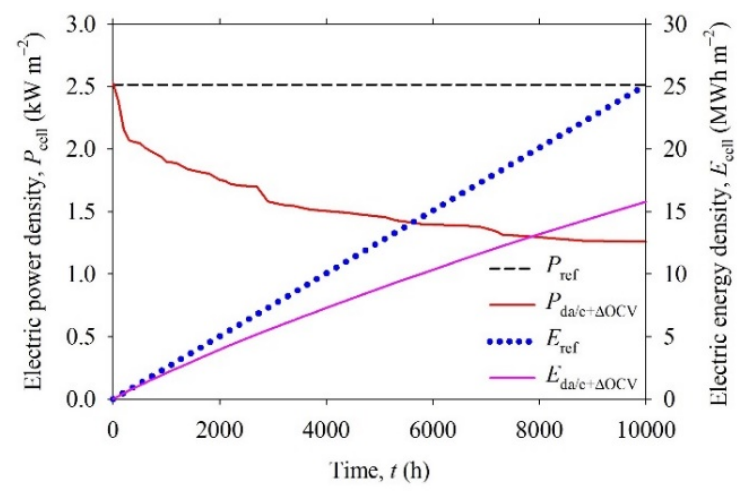

(b)

Figure 8. (a) Electric conversion efficiency ( $\eta$ ) of the SOFC as a function of time from 0 to $1000 \mathrm{~h}$. Degradation is considered in the anode $\left(\eta_{\text {da }}\right)$ layer alone, with drop of open circuit voltage $\left(\eta_{\text {da }+\Delta O C V}\right)$ and in both, anode and cathode layers, with drop of OCV $\left(\eta_{\mathrm{da} / \mathrm{c}+\Delta \mathrm{OCV}}\right)$. (b) Electric power density $\left(P_{\text {cell }}\right)$ and energy yield $\left(E_{\text {cell }}\right)$ of non-degraded $\left(P_{\text {ref }}, E_{\text {ref }}\right)$ and degraded SOFC $\left(P_{\mathrm{da} / \mathrm{c}+\Delta \mathrm{OCV}}, E_{\mathrm{da} / \mathrm{c}+\Delta \mathrm{OCV}}\right)$ as a function of time from 0 to $10,000 \mathrm{~h}$.

It is important to note that the proposed model reproduces reliable results which are closely related to the measured ones. Figure $8 \mathrm{~b}$ shows the electric power density $\left(P_{\text {cell }}\right)$ and energy density $\left(E_{\text {cell }}\right)$ of SOFC that can be calculated by Equations (25) and (26).

$$
\begin{gathered}
P_{\text {cell }}(t)=J_{\text {cell }}(t) \cdot V_{\text {cell }}(t) \\
E_{\text {cell }}(t)=\int_{0}^{t} J_{\text {cell }}(t) \cdot V_{\text {cell }}(t) \cdot d t \prime \cong \sum_{i=1}^{i=N} J_{\text {cell }}[\mathrm{i}] \cdot V_{\text {cell }}[\mathrm{i}] \cdot \Delta t
\end{gathered}
$$

The energy yield of non-degraded cell $\left(E_{\text {ref }}\right)$ equals $25.1 \mathrm{MWh} \mathrm{m}^{-2}$, whereas the energy yield of degraded cell $\left(E_{\mathrm{da} / \mathrm{c}+\Delta \mathrm{OCV}}\right)$ equals $15.8 \mathrm{MWh} \mathrm{m}^{-2}$ at $t=10,000 \mathrm{~h}$. The yield of electrical energy, generated by the real SOFC over a long time, would be much lower (by approximately $37 \%$ ) than calculated by considering the initial electric performance (i.e., the non-degraded SOFC). 
As a result, the overall cost per generated MWh of electric energy could be estimated when a high power SOFC generator was considered. This estimation is beyond the scope of the present study since the input data of the model is based on laboratory scale SOFC.

The model is very useful tool to predict the degradation rate and is suitable for online monitoring of the SOFC. However, the proposed Ni coarsening model should be improved in the future in order to consider the temperature, current density, and gas composition dependent growth of particles.

\section{Conclusions}

In this paper, the reduced-complexity, two-dimensional, microstructural model of solid oxide fuel cells (SOFC) was proposed since a numerically tractable model is sought for online evaluation of SOFC electric performance degradation. The SOFC degradation that occurs at high temperature due to the nickel agglomeration in the anode was modeled by using power law coarsening theory. The model was validated by comparing the electro-impedance spectra (EIS) of the modeled SOFC and measured EIS characteristics. The anode and cathode polarization resistances increased over the simulated time, which indicated the trends which are also observed in the real SOFC device.

The model was also validated based on the measurement data. The modeled structure was based on the backscattered electron (BSE) microscope cross-section picture of the measured SOFC. The input parameters were adjusted according to the known material parameters or fitted to match the relative density of TPBs profile and initial performances of the measured SOFC. The output voltage of the modeled SOFC closely follows the measured voltage from 0 to $1000 \mathrm{~h}$ when considering the degradation due to the grain growth in both electrodes. The absolute and relative degradation rate of electric conversion efficiency $(\eta)$ equals $0.11 \mathrm{kh}^{-1}$ and $25 \% \mathrm{kh}^{-1}$, respectively. The electric energy yield ( $E_{\text {cell }}$ ) of the degraded SOFC over the simulated time of $10,000 \mathrm{~h}$ was about $37 \%$ lower than it would be in the $E_{\text {cell }}$ of non-degraded SOFC. Moreover, the overall cost per generated MWh of electric energy could be estimated when considering a commercial SOFC stack for high electric power.

Regarding the presented results, the model was found suitable for online estimation of the degraded SOFC electric performances. Future work is going to improve the proposed degradation model by adding the temperature, current density, and gas composition dependent growth of particles.

Author Contributions: The Author reviewed available literature about modeling and characterization of solid oxide fuel cells, implemented the presented two-dimensional, microstructural model of solid oxide fuel cell in Matlab R2016b, performed extensive searching of input parameters of the model, fitted the model to match calculated and measured characteristics, made all graphic processing of the results, and wrote the entire manuscript. The author have read and agreed to the published version of the manuscript.

Funding: This research received no external funding.

Acknowledgments: The Slovenian Research Agency (ARRS) through Research Program P2-0001 and the project PR-07383 is gratefully acknowledged. The Author would also like to kindly thank Đani Juričić, for fruitful discussions and suggestions that improved the content of this paper.

Conflicts of Interest: The Author declare that there is no conflict of interest regarding the content of this article.

$\begin{array}{ll}\text { Abbreviation } & \\ 1-, 2-, 3-D & \text { One-,two-,three-dimensional } \\ \text { AC } & \text { Alternate current } \\ \text { BC } & \text { Boundary condition } \\ \text { BSE } & \text { Backscattered electron } \\ \text { CT } & \text { Computed tomography } \\ \text { DC } & \text { Direct current } \\ \text { e } & \text { Electron } \\ \text { FDM } & \text { Finite difference method }\end{array}$


FIB

GSV

LSCFLSM

MIEC

NiNi-SSZ

$\mathrm{O}^{2-}$

OCV

$\mathrm{S}$

SEM

SOFC

TPB

$X$-ray

YSZ

\section{Appendix A}

Gas Species

$\mathrm{CH}_{4}$

$\mathrm{CO}_{2}$

$\mathrm{CO}$

$\mathrm{H}_{2}$

$\mathrm{H}_{2} \mathrm{O}$

$\mathrm{N}_{2}$

$\mathrm{O}_{2}$

Symbols

$\alpha_{\mathrm{f}}^{\mathrm{a}}$

$\alpha_{\mathrm{b}}^{\mathrm{a}}$

$\alpha_{f}^{c}$

$\alpha_{b}^{\mathrm{c}}$

$\delta$

$i, j$

$\mathrm{K}$

$K_{a}$

$\underset{\mathrm{K}}{\rightarrow}$

$\vec{n}$

Quantity

$C_{\mathrm{dl}, \mathrm{a}}$

$\mathrm{C}_{\mathrm{O}^{2-}}\left[\mathrm{mol} \mathrm{m}^{-3}\right]$

$d[\mathrm{~m}]$

$D_{\text {chem }}\left[\mathrm{m}^{2} \mathrm{~s}^{-1}\right]$

$D_{\mathrm{i}, \mathrm{j}}\left[\mathrm{m}^{2} \mathrm{~s}^{-1}\right]$

$E\left[\mathrm{~J} \mathrm{~m}^{-2}\right]$

$\Delta G_{\mathrm{H}_{2}}\left[\mathrm{~J} \mathrm{~mol}^{-1}\right]$

$f[\mathrm{~Hz}]$

$F\left[\right.$ A s mol ${ }^{-1}$ ]

$\Phi\left[\mathrm{mol} \mathrm{m}^{-2} \mathrm{~s}^{-1}\right]$

$\eta[/]$

$\Delta H\left[\mathrm{~J} \mathrm{~mol}^{-1}\right]$

$i_{\mathrm{a} / \mathrm{c}}\left[\mathrm{A} \mathrm{m}^{-2}\right]$

$i_{0, \mathrm{a} / \mathrm{c}}\left[\mathrm{A} \mathrm{m}^{-2}\right]$

$j\left[\mathrm{~kg} \mathrm{~m}^{-2}\right]$

$J\left[\mathrm{~A} \mathrm{~m}^{-2}\right]$

$J_{\text {cell }}\left[\mathrm{A} \mathrm{m}^{-2}\right]$
Focused ion beam

Grey scale value

Lanthanum Strontium Cobalt FerriteLanthanum Strontium Manganite

Mixed ionic-electronic conductor

NickelNickel-scandia stabilized zirconia

Oxygen ion

Open circuit voltage

Sulfur

Scanning electronic microscopy

Solid oxide fuel cell

Triple-phase boundary

High-energy electromagnetic radiation

Yttria-stabilized zirconia

\author{
Methane \\ Carbon dioxide \\ Carbon monoxide \\ Hydrogen \\ Water \\ Nitrogen \\ Oxygen
}

Forward anode exponential coefficient

Backward anode exponential coefficient

Forward cathode exponential coefficient

Backward cathode exponential coefficient

Delta function

Indexes of gas species

Exponential coefficient

Anode exponential coefficient

Cathode exponential coefficient

Normal unit vector

Double layer capacitance of anode

Concentration of oxygen ions

Diameter of nickel grains

Chemical diffusion coefficient

Diffusion coefficient of gas species

Energy density

Gibbs free energy for hydrogen

Frequency

Faraday constant

Molar flux density

Conversion efficiency

Standard enthalpy of formation

Anode/cathode current density

Anode/cathode exchange current density

Diffusive mass flux

Current density

Output current density of SOFC 


$\begin{array}{ll}k_{\mathrm{a} / \mathrm{c}}\left[\mathrm{m}^{3} \mathrm{~s}^{-1}\right] & \text { Anode/cathode growth coefficient } \\ k_{\mathrm{surf}}\left[\mathrm{m} \mathrm{s}^{-1}\right] & \text { Surface exchange coefficient } \\ k_{\mathrm{th}}\left[\mathrm{V} \mathrm{K}^{-1}\right] & \text { Temperature coefficient } \\ \mu[/] & \text { Porosity } \\ M\left[\mathrm{~kg} \mathrm{~mol}^{-1}\right] & \text { Molar mass } \\ p\left[\mathrm{~kg} \mathrm{~m}^{-1} \mathrm{~s}^{-1}\right] & \text { Pressure } \\ P\left[\mathrm{~W} \mathrm{~m}^{-2}\right] & \text { Power density } \\ \rho\left[\mathrm{kg} \mathrm{m}^{-3}\right] & \text { Density of gas } \\ R\left[\mathrm{~J} \mathrm{~mol}^{-1} \mathrm{~K}^{-1}\right] & \text { Ideal gas constant } \\ R_{\mathrm{s}}\left[\Omega \mathrm{cm}^{2}\right] & \text { Series resistance } \\ \delta\left[\mathrm{S} \mathrm{m}{ }^{-1}\right] & \text { Electronic or ionic conductivity } \\ S\left[\mathrm{~kg} \mathrm{~s}{ }^{-1}\right] & \text { Source or sink term } \\ t[\mathrm{~s}] & \text { Time } \\ T[\mathrm{~K}] & \text { Temperature } \\ v\left[\mathrm{~m} \mathrm{~s} \mathrm{~s}^{-1}\right] & \text { Velocity } \\ V_{\mathrm{cell}}[\mathrm{V}] & \text { Output voltage of SOFC } \\ V_{\mathrm{el}}[\mathrm{V}] & \text { Electrolyte phase potential } \\ V_{\mathrm{s}}[\mathrm{V}] & \text { Solid phase potential } \\ V_{\mathrm{i}}\left[\mathrm{m}^{3}\right] & \text { Diffusion volume of } i \text {-th gas specie } \\ x_{\mathrm{i}}[/] & \text { Molar fraction of the } i \text {-th gas specie } \\ y_{\mathrm{i}}[/] & \text { Mass fraction of the } i \text {-th gas specie } \\ \eta[/] & \text { Conversion efficiency }\end{array}$

\section{References}

1. Ali Saadabadi, S.; Thallam Thattai, A.; Fan, L.; Lindeboom, R.E.F.; Spanjers, H.; Aravind, P.V. Solid Oxide Fuel Cells fuelled with biogas: Potential and constraints. Renew. Energy 2019, 134, 194-214. [CrossRef]

2. Huang, K.; Goodenough, J.B. Direct current (DC) electrical efficiency and power of a solid oxide fuel cell (SOFC). In Solid Oxide Fuel Cell Technology: Principles, Performance and Operations; Woodhead Publishing Limited, Abington Hall, Granta Park, Great Abington: Cambridge, UK, 2009; pp. 141-148.

3. Chatrattanawet, N.; Saebea, D.; Authayanun, S.; Arpornwichanop, A.; Patcharavorachot, Y. Performance and environmental study of a biogas-fuelled solid oxide fuel cell with different reforming approaches. Energy 2018, 146, 131-140. [CrossRef]

4. Kupecki, J.; Papurello, D.; Lanzini, A.; Naumovich, Y.; Motylinski, K.; Blesznowski, M.; Santarelli, M. Numerical model of planar anode supported solid oxide fuel cell fed with fuel containing $\mathrm{H}_{2} \mathrm{~S}$ operated in direct internal reforming mode (DIR-SOFC). Appl. Energy 2018, 230, 1573-1584. [CrossRef]

5. Moçoteguy, P.; Brisse, A. A review and comprehensive analysis of degradation mechanisms of solid oxide electrolysis cells. Int. J. Hydrogen Energy 2013, 38, 15887-15902. [CrossRef]

6. Papurello, D.; Lanzini, A.; Fiorilli, S.; Smeacetto, F.; Singh, R.; Santarelli, M. Sulfur poisoning in Ni-anode solid oxide fuel cells (SOFCs): Deactivation in single cells and a stack. Chem. Eng. J. 2016, 283, 1224-1233. [CrossRef]

7. Lanzini, A.; Leone, P.; Guerra, C.; Smeacetto, F.; Brandon, N.P.; Santarelli, M. Durability of anode supported Solid Oxides Fuel Cells (SOFC) under direct dry-reforming of methane. Chem. Eng. J. 2013, 220, 254-263. [CrossRef]

8. Yu, R.; Guan, W.; Wang, F.; Han, F. Quantitative assessment of anode contribution to cell degradation under various polarization conditions using industrial size planar solid oxide fuel cells. Int. J. Hydrogen Energy 2018, 43, 2429-2435. [CrossRef]

9. Hubert, M.; Laurencin, J.; Cloetens, P.; Morel, B.; Montinaro, D.; Lefebvre-Joud, F. Impact of Nickel agglomeration on Solid Oxide Cell operated in fuel cell and electrolysis modes. J. Power Sources 2018, 397, 240-251. [CrossRef]

10. Khan, M.Z.; Mehran, M.T.; Song, R.H.; Lee, J.W.; Lee, S.B.; Lim, T.H. A simplified approach to predict performance degradation of a solid oxide fuel cell anode. J. Power Sources 2018, 391, 94-105. [CrossRef]

11. Lei, Y.; Cheng, T.L.; Wen, Y.H. Phase field modeling of microstructure evolution and concomitant effective conductivity change in solid oxide fuel cell electrodes. J. Power Sources 2017, 345, 275-289. [CrossRef] 
12. Cuneo, A.; Zaccaria, V.; Tucker, D.; Traverso, A. Probabilistic analysis of a fuel cell degradation model for solid oxide fuel cell and gas turbine hybrid systems. Energy 2017, 141, 2277-2287. [CrossRef]

13. Zhu, J.; Lin, Z. Degradations of the electrochemical performance of solid oxide fuel cell induced by material microstructure evolutions. Appl. Energy 2018, 231, 22-28. [CrossRef]

14. Fuller, E.N.; Schettler, P.D.; Giddings, J.C. A new method for prediction of binary gas-phase diffusion coefficients. Ind. Eng. Chem. 1966, 58, 19-27. [CrossRef]

15. Nerat, M.; Juričić, Đ. A comprehensive 3-D modeling of a single planar solid oxide fuel cell. Int. J. Hydrogen Energy 2016, 41, 3613-3627. [CrossRef]

16. Søgaard, M.; Vang Hendriksen, P.; Jacobsen, T.; Mogensen, M. Modelling of the Polarization Resistance from Surface Exchange and Diffusion Coefficient Data. In Proceedings of the 7th European SOFC Forum, Lucerne, Switzerland, 3-7 July 2006.

17. Joos, J. Microstructural Characterisation, Modelling and Simulation of Solid Oxide Fuel Cell Cathodes. In Dissertation, Karlsruher Institut für Technologie, KIT-Fakultät für Elektrotechnik und Informationstechnik; D-KIT Scientific Publishing: Karlsruhe, Germany, 2017.

18. Otsu, N. A threshold selection method from gray-level histogram. IEEE Trans. Syst. Man Cybern. 1979, 9, 62-66. [CrossRef]

19. Sahoo, P.K.; Saltani, S.; Wong, A.K.C. A survey of thresholding techniques. Comp. Vis. Graph. Image Process. 1988, 41, 233-260. [CrossRef]

20. Münch, B.; Holzer, L. Contradicting Geometrical Concepts in Pore Size Analysis Attained with Electron Microscopy and Mercury Intrusion. J. Am. Ceram. Soc. 2008, 91, 4059-4067. [CrossRef]

21. Wilson, J.R.; Kobsiriphat, W.; Mendoza, R.; Chen, H.Y.; Hiller, J.M.; Miller, D.J.; Thornton, K.; Voorhees, P.W.; Adler, S.B.; Barnett, S.A. Three-dimensional reconstruction of a solid-oxide fuel-cell anode. Nat. Mater. 2006, 5, 541-544. [CrossRef]

22. Izzo, J.R.; Joshi, A.S.; Grew, K.N.; Chiu, W.K.S.; Tkachuk, A.; Wang, S.H.; Yun, W. Nondestructive Reconstruction and Analysis of SOFC Anodes Using X-ray Computed Tomography at Sub-50 nm Resolution. J. Electrochem. Soc. 2008, 155, B504-B508. [CrossRef]

23. Yan, Z.; He, A.; Hara, S.; Shikazono, N. Modeling of solid oxide fuel cell (SOFC) electrodes from fabrication to operation: Correlations between microstructures and electrochemical performances. Energy Convers. Manag. 2019, 190, 1-13. [CrossRef]

24. Liu, Y.L.; Thydén, K.; Chen, M.; Hagen, A. Microstructure degradation of LSM-YSZ cathode in SOFCs operated at various conditions. Solid State Ion. 2012, 206, 97-103. [CrossRef]

25. Zekri, A.; Knipper, M.; Parisi, J.; Plaggenborg, T. Microstructure degradation of Ni/CGO anodes for solid oxide fuel cells after long operation time using 3D reconstructions by FIB tomography. Phys. Chem. Chem. Phys. 2017, 19, 13767-13777. [CrossRef] [PubMed]

26. Holzer, L.; Iwanschitz, B.; Hocker, T.; Münch, B.; Prestat, M.; Wiedenmann, D.; Vogt, U.; Holtappels, P.; Sfeir, J.; Mai, A.; et al. Microstructure degradation of cermet anodes for solid oxide fuel cells: Quantification of nickel grain growth in dry and in humid atmospheres. J. Power Sources 2011, 196, 1279-1294. [CrossRef]

27. Bertei, A.; Nucci, B.; Nicolella, C. Microstructural modeling for prediction of transport properties and electrochemical performance in SOFC composite electrodes. Chem. Eng. Sci. 2013, 101, 175-190. [CrossRef]

28. Lay-Grindler, E.; Laurencin, J.; Villanova, J.; Cloetens, P.; Bleuet, P.; Mansuy, A.; Mougin, J.; Delette, G. Degradation study by 3D reconstruction of a nickel-yttria stabilized zirconia cathode after high temperature steam electrolysis operation. J. Power Sources 2014, 269, 927-936. [CrossRef]

29. Brune, A.; Lajavardi, M.; Fisler, D.; Wagner, J.B. The electrical conductivity of yttria-stabilized zirconia prepared by precipitation from inorganic aqueous solutions. Solid State Ion. 1998, 106, 89-101. [CrossRef]

30. Cronin, J.S.; Wilson, J.R.; Barnett, S.A. Impact of pore microstructure evolution on polarization resistance of Ni-Yttria-stabilized zirconia fuel cell anodes. J. Power Sources 2011, 196, 2640-2643. [CrossRef]

(C) 2020 by the author. Licensee MDPI, Basel, Switzerland. This article is an open access article distributed under the terms and conditions of the Creative Commons Attribution (CC BY) license (http://creativecommons.org/licenses/by/4.0/). 